\title{
Efficacy of Hallux Valgus Deformity Correction Exercise Program in Young Females
}

\author{
Kajol Kulkarni ${ }^{1 *}$ and Chandrakant Patil ${ }^{2}$ \\ 'Faculty of Physiotherapy, Krishna Institute of Medical Sciences "Deemed to Be University" Karad - 415110, Maharashtra, \\ India; kajolkulkarni18@gmail.com \\ 2Department of Cardiopulmonary Sciences, Faculty of Physiotherapy, Krishna Institute of Medical Sciences "Deemed to Be \\ University", Karad - 415110, Maharashtra, India
}

\begin{abstract}
Background: Hallux valgus deformity mostly seen in females because of high heels and tight/narrow shoes. Previous studies have focused on surgical treatment, orthosis, footwear modifications and tapping, but this not correct valgus deformity and causes certain complications. No studies are conducted showing proper exercise program effective in decreasing the valgus angle. The purpose of this study was to determine the efficacy of hallux valgus deformity correction exercise program in young females. Objectives: To determine the efficacy of hallux valgus deformity correction exercise program in young females. Methods: 24 female subjects with mild and moderate hallux valgus angle were divided, in group A (experimental) treated with deformity correction exercises, mobilization, stretching and group B (control) with toe spread out and short foot exercises. A goniometer was used to determine the valgus angle of great toe. Visual analogue scale for the pain and functional limitations was evaluated by using Foot and Ankle Disability Index. Results: On comparing both groups, there was no statistically significant difference seen in pre interventional values. In post interventional values, there was significant difference seen with $p$ value for pain at rest $(<0.0001)$ and on activity $(<0.0001)$, goniometric range of motion of great toe of right $(<0.0002)$ and left side $(<0.0003)$, foot and ankle disability index score $(<0.0238)$. Conclusion: The conducted study shows that deformity correction exercises, stretching and mobilization had more beneficial effects than toe spread out and short foot exercises for correcting the deformity.
\end{abstract}

Keywords: Deformity Correction Exercises, Movement with Mobilization, Strengthening, Stretching

\section{Introduction}

Hallux valgus is most common foot deformity. The prevalence rate in adult population ages between 20 to 64 were about $33 \%^{1}$.

It is a complex, painful, progressive deformity with lateral deviation of the great toe and medial deviation of the $1^{\text {st }}$ metatarsal. This will increase the valgus angle. The angle created between the lines that longitudinally bisect the proximal phalanx and $1^{\text {st }}$ metatarsal. An angle of $<15^{\circ}$ considered normal, $15^{\circ}-20^{\circ}$ mild, $20^{\circ}-40^{\circ}$ moderate and $>40^{\circ}$ considered severe ${ }^{2}$.

Over pronation of foot, Achilles tendon contractures, adductor and abductor halluces muscle imbalance, hypermobility of $1^{\text {st }}$ metatarsocuneiform joint, increased joint laxity, acquired flat foot, low transverse arch are the main intrinsic factors. Wearing high heels and tight/narrow shoes that constrict the forefoot are extrinsic factor. So, it is more common among women and young individuals. Those individuals involved in daily standing professions, having longer walking distance and uneven surface of ambulation are the major risk factors for developing such complaints which will further affect their activity causing physical limitations while performing a task ${ }^{3}$.

This deformity causes pain, inflammation and decreased joint mobility in great toe ${ }^{4}$. If this remains untreated, it will lead to pathological changes in gait and plantar pressure, range of motion limitation in foot joints, pain during walking and movement, problems in choosing comfortable shoes 5 .

The motive of this study was to correct the deformity by decreasing the valgus angle and pain, improving functional performance of foot and ankle. Physiotherapy treatment was beneficial in treating this deformity.

Movement with mobilization is manual therapy technique in which therapist apply sustained accessory mobilization

${ }^{*}$ Author for correspondence 
to joint and patient has to perform the action of the specific muscle/joint. This was used to improve joint range of motion, reducing pain, muscle guarding and enhance muscle function ${ }^{6}$.

Stretching and strengthening are also effective in reducing hallux valgus angle. It was applied with proper stabilization and adequate intensity ${ }^{7}$. Stretching and Strengthening was given to adductor and abductor hallucis respectively, to increase muscle flexibility and strength, improve muscle performance, decrease risk of injuries and help the joints to move through their full range of motion ${ }^{8}$.

Foot exercises also important in order to maintain the joint mobility, stretching soft tissues around the joint and to improve the muscle strength ${ }^{9}$. The exercises which were included in our protocol was toe spread out, passive toe circles, towel grip and pull, ball roll, assisted toe abduction with exercise band, passive abduction of hallux with traction of $1^{\text {st }}$ metatarsophalangeal joint, double leg heel raises with calf squeeze in standing, manual stretching, movement with mobilization, cryotherapy ${ }^{10}$.

Most of the previous studies focused on use of orthosis, tapping and footwear modification was suitable treatment to correct the deformity ${ }^{11}$. Surgery was also performed in these patients shows prolonged recovery rate, high cost, cosmetic issues and complications like infection, nerve injury, failure to relieve pain and bone healing, stiffness of the great toe joint, bunion recurrence and cosmetic issues. Although surgical treatment has high recurrence rate $^{12}$. There was no study focused on deformity correction exercises. Our study will bridge this gap by providing the more knowledge about the deformity corrective exercises along with stretching, mobilization. So, the purpose of this study was to determine the efficacy of hallux valgus deformity correction exercise program in young females.

\section{Materials and Methods}

This experimental study was carried out in Krishna college of physiotherapy, deemed to be university, Karad.

Subject Criteria: This study was conducted over 20 days period. 24 female subjects between ages of 18 to 50 years with hallux valgus were included in this study. Inclusion criteria were a metatarsophalangeal angle of toe $>15^{\circ}$ and $<40^{\circ}$, female subjects. Exclusion criteria were subjects with angle $>40^{\circ}$, foot surgeries, any other foot deformities, systemic disease, neurological, cognitive, mental/psychological problems.

Procedure: Ethical approval was taken from institutional Protocol and ethical committee of Krishna Institute of Medical Sciences Deemed to Be University. Subjects were selected as per inclusion and exclusion criteria. Nature of the study were explained prior to subjects. Informed consents and demographic data were taken from each subject. The valgus angle of great toe was measured using Goniometer, pain taken by using Visual Analogue Scale and functional limitations of foot and ankle taken based on foot and ankle disability index. The pre-treatment measures were documented. The subjects were divided into 2 groups. Experimental group were treated with deformity correction exercises, movement with mobilization, manual stretching and control group with toe spread out and short foot exercises. All the subjects were re-evaluated at the end of 20 days period for comparison of post treatment values.

Protocol: 2-3 times/day for 20 days

A. Experimental group: Deformity correction exercises

1) Toe spread out - 10 times $x$ 3-5 sets

2) Passive toe circles (clockwise and anticlockwise) - 10 times $\times 3-5$ sets

3) Towel grip and pull - 10-15 times

4) Ball roll - 3-5 minutes

5) Assisted toe abduction with exercise band - 10 times, 3 sets

6) Passive abduction of the hallux with traction of first metatarsophalangeal joint - 10 repetitions

7) Double leg heel raises with calf squeeze in standing - 10 repetitions, 5 sec hold

8) Manual stretching - agonist contraction exercises Resistance $30 \mathrm{sec}, 15 \mathrm{sec}$ breaks for each set, 10 sets

9) Manual stretching - agonist contraction and hold- relax exercises - Contraction maintains $25 \mathrm{sec}$, stretch $10 \mathrm{sec}$, $15 \mathrm{sec}$ rest, 10 sets

10) Manual medial glide MWM with

- Flexion -6 repetitions $x 3$ sets

- Extension -6 repetitions $x 3$ sets

11) Cryotherapy - 5-10 minutes

B. Control group: Foot exercises

1) Toe spread out- 10 times $x 3-5$ sets

2) Short foot exercises- 10 times $x$ 3-5 sets

\section{Outcome Measures}

By using goniometer, the valgus angle of both right and left leg great toe was measured. The fulcrum of goniometer was at the $1^{\text {st }}$ metatarsophalangeal joint, fixed arm placed parallel to $1^{\text {st }}$ metatarsal bone, movable arm placed parallel to the lateral border of proximal phalanx of great toe. The value was recorded by the angle formed between these 2 lines.

The pain was evaluated by using visual analogue scale was ranged from 0 (no pain) to 10 (worst pain). The subjects were asked to mark their pain at rest and on activity on 10-point scale. The markings on those lines were measured in centimetres and results were recorded. 
Functional limitations of foot and ankle were determined by using Foot and ankle disability scale. It has 22 items, was scored on 5-point scale from 0 (unable to do) to 4 (no difficulty at all). The pain has 4 items was scored on 5-point scale from 0 (none) to 4 (unbearable). The scale has total 104 points and were scored as percentages. More the \%, lesser the disability.

\section{Statistical Analysis}

The outcome measures were assessed at the baseline. The collected data in this study was statistically analysed using descriptive statistics as mean, standard deviation. The paired $t$ test was used to investigate the pre and post treatment difference between the groups. Unpaired t-test was used to investigate the comparison between 2 groups after post treatment. The statistical significance was confirmed according to p-value.

\section{Results}

Table 1. Demographic data

\begin{tabular}{|l|l|l|}
\hline & $\begin{array}{l}\text { Experimental group } \\
(\mathbf{A}) \\
(\mathbf{n}=\mathbf{1 2}) \\
(\text { Mean } \pm \text { SD })\end{array}$ & $\begin{array}{l}\text { Control group } \\
(\mathbf{B}) \\
(\mathbf{n = 1 2}) \\
(\text { Mean } \pm \text { SD })\end{array}$ \\
\hline Age $($ Year $)$ & $23.91 \pm 6.64$ & $27.58 \pm 8.55$ \\
\hline BMI $\left(\mathbf{K g} / \mathbf{m}^{2}\right)$ & $20.35 \pm 2.80$ & $21.75 \pm 3.09$ \\
\hline
\end{tabular}

BMI: body mass index, SD: standard deviation

Table 1 shows that the average mean of age was $23.91 \pm 6.64$ for Group A, 27.58 \pm 8.55 for Group B and for body mass index $20.35 \pm 2.80$ for Group A and 21.75 \pm 3.09 for Group B.

Table 2. Pre and post treatment scores within the group

\begin{tabular}{|c|c|c|c|c|c|c|c|}
\hline Sr No. & & & $\begin{array}{c}\text { Pre-Test } \\
(\text { Mean } \pm \text { SD })\end{array}$ & $\begin{array}{c}\text { Post Test } \\
(\text { Mean } \pm \text { SD })\end{array}$ & $\begin{array}{c}\text { Mean } \\
\text { Difference }\end{array}$ & Paired ' $t$ ' value & $P$ value \\
\hline & \multicolumn{7}{|c|}{ Experimental group (A) } \\
\hline \multirow{2}{*}{1.} & Pain & At rest & $2.33 \pm 0.49$ & $0.25 \pm 0.45$ & 2.083 & 14.015 & $<0.0001$ \\
\hline & & On activity & $4.76 \pm 1.04$ & $2.02 \pm 0.21$ & 2.742 & 10.875 & $<0.0001$ \\
\hline \multirow{2}{*}{2.} & \multirow{2}{*}{$\begin{array}{c}\text { Range of } \\
\text { Motion of great } \\
\text { toe }\end{array}$} & Right & $17.66 \pm 2.49$ & $12.75 \pm 0.62$ & 4.917 & 8.429 & $<0.0001$ \\
\hline & & Left & $19.5 \pm 3.37$ & $12.66 \pm 0.65$ & 6.833 & 7.944 & $<0.0001$ \\
\hline \multirow[t]{2}{*}{3.} & \multicolumn{2}{|c|}{ Foot and Ankle Disability Index } & $72.51 \pm 3.85$ & $83.53 \pm 3.13$ & -11.020 & 12.195 & $<0.0001$ \\
\hline & \multicolumn{7}{|c|}{ Control group (B) } \\
\hline \multirow{2}{*}{1.} & \multirow{2}{*}{ Pain } & At rest & $2.58 \pm 0.51$ & $1.41 \pm 0.66$ & 1.167 & 10.383 & $<0.0001$ \\
\hline & & On activity & $5.75 \pm 0.71$ & $3.76 \pm 0.54$ & 1.983 & 16.046 & $<0.0001$ \\
\hline \multirow{2}{*}{2.} & \multirow{2}{*}{$\begin{array}{c}\text { Range of } \\
\text { Motion of great } \\
\text { toe }\end{array}$} & Right & $17.75 \pm 1.42$ & $13.75 \pm 0.45$ & 4.000 & 10.832 & $<0.0001$ \\
\hline & & Left & $17.58 \pm 1.31$ & $13.66 \pm 0.49$ & 3.917 & 10.346 & $<0.0001$ \\
\hline 3. & \multicolumn{2}{|c|}{ Foot and Ankle Disability Index } & $70.10 \pm 1.76$ & $80.28 \pm 3.41$ & -10.181 & 8.852 & $<0.0001$ \\
\hline
\end{tabular}

${ }^{*} \mathrm{p}<0.0001$, extremely significant, $\mathrm{SD}$ : standard deviation 
Table 2 show that shows that, in Group A, pre-treatment mean of pain at rest was $2.33 \pm 0.49$ and on activity $4.76 \pm 1.04$, range of motion of great toe of right side $17.66 \pm 2.49$ and left side 19.5 \pm 3.37 , foot and ankle disability index score were 72.51 \pm 3.85 . Post treatment mean of pain at rest $0.25 \pm 0.45$ was and on activity $2.02 \pm 0.21$, range of motion of great toe of right side $12.75 \pm 0.62$ and left side $12.66 \pm 0.65$, foot and ankle disability index score were $83.53 \pm 3.13$. In group $B$, pretreatment mean of pain at rest $2.58 \pm 0.51$ was and on activity
$5.75 \pm 0.71$, range of motion of great toe of right side $17.75 \pm 1.42$ and left side $17.58 \pm 1.31$, foot and ankle disability index score were $70.10 \pm 1.76$. Post treatment mean of pain at rest $1.41 \pm 0.66$ was and on activity $3.76 \pm 0.54$, range of motion of great toe of right side $13.75 \pm 0.45$ and left side $13.66 \pm 0.49$, foot and ankle disability index score were $80.28 \pm 3.41$. The intra group analysis was revealed that there was significant decrease in pain, range of motion and foot and ankle disability index score after post treatment in both groups.

Table 3. Comparison of pre-treatment scores between group

\begin{tabular}{|c|c|c|c|c|c|c|c|}
\hline Sr No. & & & $\begin{array}{c}\text { Experimental } \\
\text { group }(\mathrm{A}) \\
(\text { Mean } \pm \text { SD }) \\
\end{array}$ & $\begin{array}{c}\text { Control group } \\
\text { (B) } \\
(\text { Mean } \pm \text { SD }) \\
\end{array}$ & $\begin{array}{c}\text { Mean } \\
\text { Difference }\end{array}$ & $\begin{array}{l}\text { Unpaired ' } t \text { ' } \\
\text { value }\end{array}$ & $P$ value \\
\hline \multirow{2}{*}{1.} & Pain & At rest & $2.33 \pm 0.49$ & $2.58 \pm 0.51$ & 0.2500 & 1.224 & $<0.2337$ \\
\hline & & On activity & $4.76 \pm 1.04$ & $5.75 \pm 0.71$ & 0.9900 & 2.723 & $<0.0124$ \\
\hline \multirow{2}{*}{2.} & \multirow{2}{*}{$\begin{array}{l}\text { Range of } \\
\text { Motion of } \\
\text { great toe }\end{array}$} & Right & $17.66 \pm 2.49$ & $17.75 \pm 1.42$ & 0.0900 & 0.1088 & $<0.9144$ \\
\hline & & Left & $19.5 \pm 3.37$ & $17.58 \pm 1.31$ & 1.920 & 1.840 & $<0.0794$ \\
\hline 3. & \multicolumn{2}{|c|}{ Foot and Ankle Disability Index } & $72.51 \pm 3.85$ & $70.10 \pm 1.76$ & -2.410 & 1.972 & $<0.0613$ \\
\hline
\end{tabular}

SD: standard deviation

Table 3 shows that, the pre-interventional mean of pain at rest was 2.33 \pm 0.49 , on activity 4.76 \pm 1.04 for Group A and for Group $\mathrm{B}$ at rest $2.58 \pm 0.51$, on activity $5.75 \pm 0.71$. For range of motion of great toe of right side was $17.66 \pm 2.49$, left side $19.5 \pm 3.37$ for Group A and right side $17.75 \pm 1.42$, left side $17.58 \pm 1.31$ for Group B. The foot and ankle disability index score for Group A was $72.51 \pm 3.85$ and $70.10 \pm 1.76$ for Group B. This study shows that there was no significant difference between the pre-intervention inter-group analysis $\mathrm{p}<0.2337, \mathrm{p}<0.0124, \mathrm{p}<0.9144, \mathrm{p}<0.0794, \mathrm{p}<0.0613$ respectively.

Table 4. Comparison of post-treatment scores between group

\begin{tabular}{|c|c|c|c|c|c|c|c|}
\hline $\begin{array}{l}\text { Sr } \\
\text { No. }\end{array}$ & & & $\begin{array}{c}\text { Experimental } \\
\text { group } \\
(\mathrm{A}) \\
(\text { Mean } \pm \mathrm{SD})\end{array}$ & $\begin{array}{c}\text { Control group } \\
\text { (B) } \\
(\text { Mean } \pm \text { SD })\end{array}$ & Mean Difference & $\begin{array}{l}\text { Unpaired ' } t \text { ' } \\
\text { value }\end{array}$ & $P$ value \\
\hline \multirow[t]{2}{*}{1.} & \multirow[t]{2}{*}{ Pain } & At rest & $0.25 \pm 0.45$ & $1.41 \pm 0.66$ & 1.160 & 5.030 & $<0.0001$ \\
\hline & & On activity & $2.02 \pm 0.21$ & $3.76 \pm 0.54$ & 3.740 & 22.361 & $<0.0001$ \\
\hline \multirow[t]{2}{*}{2.} & \multirow{2}{*}{$\begin{array}{c}\text { Range of } \\
\text { Motion of great } \\
\text { toe }\end{array}$} & Right & $12.75 \pm 0.62$ & $13.75 \pm 0.45$ & 1.000 & 4.522 & $<0.0002$ \\
\hline & & Left & $12.66 \pm 0.65$ & $13.66 \pm 0.49$ & 1.000 & 4.256 & $<0.0003$ \\
\hline 3. & \multicolumn{2}{|c|}{ Foot and Ankle Disability Index } & $83.53 \pm 3.13$ & $80.28 \pm 3.41$ & -3.250 & 2.429 & $<0.0238$ \\
\hline
\end{tabular}

${ }^{*} \mathrm{p}<0.0001$, considered significant, SD: standard deviation

Table 4 shows that, the post-interventional mean of pain at rest was $0.25 \pm 0.45$, on activity $2.02 \pm 0.21$ for Group A and for Group B at rest $1.41 \pm 0.66$, on activity $3.76 \pm 0.54$. For range of motion of great toe of right side was $12.75 \pm 0.62$, left side $12.66 \pm 0.65$ for group A and right side 13.75 \pm 0.45 , left side $13.66 \pm 0.49$ for Group B. the foot and ankle disability index score for group A was $83.53 \pm 3.13$ and $80.28 \pm 3.41$ for Group B. This study shows that the post-intervention score was statistically significant between 2 groups $\mathrm{p}<0.0001, \mathrm{p}<0.0001 \mathrm{p}<0.0002, \mathrm{p}<0.0003, \mathrm{p}<0.0238$. Post intervention score was reduced more in Group A than Group B. 


\section{Discussion}

The aim of this study was to find out the efficacy of hallux valgus deformity correction exercise program in young females. Hallux valgus was occurred due to prolonged pressure applied to the hallux associated with wearing tight/narrow shoes. This results in shortening of (agonist) adductor and weakening of (antagonist) abductor hallucis muscle, causes increased valgus angle, produces pain, inflammation and decreased joint mobility in great toe. If neglected, it produces further problems such as pathological changes in gait and plantar pressure, limitation in range of motion of foot joints, pain during walking and movement, choosing comfortable shoes. So, treatment was given as early as possible to reduce the further risk.

The study conducted by $\mathrm{Wu}$ et. al. ${ }^{14}$ stated that the prevalence rate of hallux valgus in young adult population were about $33 \%$. Wearing high heels/tight shoes increases the pressure on forefoot by $76 \%$. About $83 \%$ peoples who had hallux valgus indicating the family history ${ }^{1}$.

The previous studies focused more on taping, foot orthosis, surgical treatment, footwear modifications. But didn't give good results, instead it produces prolonged recovery rate, high cost, cosmetic issues and some complications which indirectly affects the overall gait and posture of the person ${ }^{13}$. So, it is important to make more attention towards conservative approach with therapeutic techniques for correcting this deformity and improving functional performance of foot and ankle ${ }^{14}$.

Intrinsic muscles of the foot are providing the stability, support foot arch and maintain foot position ${ }^{15}$. Our study mainly focused on providing conservative treatment approach to intrinsic foot muscles in order to correct the hallux valgus deformity. The main purpose of the conservative treatment was to increase the valgus angle, decrease pain, improving foot functional performance and to prevent the deformity becoming worse.

We divided the female subjects randomly into 2 groups. Group A (experimental) treated with foot exercises such as toe spread out, clockwise and anticlockwise passive toe circles, towel grip and pull, ball roll, assisted toe abduction with exercise band, passive abduction of the hallux with traction of $1^{\text {st }}$ metatarsophalangeal joint, double leg heel raises with calf squeeze in standing, manual stretching and movement with mobilization, cryotherapy. Group B (control) treated with toe spread out and short foot exercises.

All the subjects were evaluated for pre and post treatment pain at rest and on activity, measurement of valgus angle of great toe and functional performance using foot and ankle disability index. Then the outcome measures were calculated with help of paired and unpaired $t$ test. After 20 days of treatment program subjects were re-evaluated. The result of our study shows that, there were reduction in the post treatment values in both groups but more in experimental than control group. The statistical analysis between 2 groups, values was for pain at rest $(t=5.030, p<0.0001)$ and on activity $(t=22.361, p<0.0001)$, for range of motion of great toe of right side $(\mathrm{t}=4.522, \mathrm{p}<0.0002)$ and left side $(\mathrm{t}=4.256, \mathrm{p}<0.0003)$, for foot and ankle disability index score $(t=2.429, \mathrm{p}<0.0238)$. This shows that, our treatment was very effective in young females for correction of hallux valgus deformity.

Every study that was conducted has limitations. In our study, the limitations were less sample size, short duration protocol, only females were included. So, it is recommended that, further studies should make more attention towards these limitations for more effectiveness of the study.

\section{Conclusion}

On the basis of results, we have concluded that deformity correction exercises with mobilization and stretching had more beneficial effects as compared to toe spread out and short foot exercises in decreasing hallux valgus angle, pain, improving functional performance of foot and ankle.

\section{Acknowledgement}

We express our sincere gratitude to all the people who have directly or indirectly contributed and helped us to conduct this research. We could also thank Krishna Institute of Medical Sciences Deemed to Be University, Karad who funded this project and helped us by all possible means.

\section{References}

1. Arge A, Lenzner A, Gapeyeva H, Pääsuke M. Range of motion and pain intensity of the first metatarsophalangeal joint in women with hallux valgus deformation after two-month home exercise programme. Acta Kinesiologiae Universitatis Tartuensis. 2012; 18:111-8. https://doi.org/10.12697/akut.2012.18.12

2. Bayar B, Erel S, Şimşek İE, Sümer E, Bayar K. The effects of taping and foot exercises on patients with hallux valgus: A preliminary study. Turkish Journal of Medical Sciences. 2011; 41(3):403-9.

3. Cho NH, Kim S, Kwon DJ, Kim HA. The prevalence of hallux valgus and its association with foot pain and function in a rural Korean community. The Journal of Bone and Joint Surgery. 2009; 91(4):494-8. https://doi.org/10.1302/0301-620X.91B4.21925. PMid:19336810

4. Coşkun G, Talu B, Bek N, Bayramlar KY. Effects of hallux valgus deformity on rear foot position, pain, function, and quality of life of women. Journal of Physical Therapy Science. 2016; 28(3):7817. https://doi.org/10.1589/jpts.28.781. PMid:27134358. PMCid: PMC4842439 
5. Easley ME, Trnka HJ. Current concepts review: hallux valgus part 1: Pathomechanics, clinical assessment, and nonoperative management. Foot \& Ankle International. 2007; 28(5):654-9. https://doi.org/10.3113/FAI.2007.0654. PMid:17559782

6. Fraissler L, Konrads C, Hoberg M, Rudert M, Walcher M. Treatment of hallux valgus deformity. EFORT open reviews. 2016 Aug; 1(8):295-302. https://doi.org/10.1302/2058-5241.1.000005. PMid:28660074. PMCid:PMC5467633

7. Glasoe WM. Treatment of progressive first metatarsophalangeal hallux valgus deformity: A biomechanically based musclestrengthening approach. Journal of Orthopaedic and Sports Physical Therapy. 2016; 46(7):596-605. https://doi.org/10.2519/ jospt.2016.6704. PMid:27266887

8. Hong WP, Ryu BH, Lee SB. Comparison of joint mobilization with manual stretching exercises in the treatment of hallux valgus. Journal of International Academy of Physical Therapy Research. 2018; 9(4):1614-8. https://doi.org/10.20540/ JIAPTR.2018.9.4.1614

9. Hurn SE, Vicenzino BT, Smith MD. Non-surgical treatment of hallux valgus: A current practice survey of Australian podiatrists. Journal of Foot and Ankle Research. 2016 Dec; 9(1):1-9. https://doi.org/10.1186/s13047-016-0146-5. PMid:27148407. PMCid:PMC4855349

10. Kim MH, Kwon OY, Kim SH, Jung DY. Comparison of muscle activities of abductor hallucis and adductor hallucis between the short foot and toe-spread-out exercises in subjects with mild hallux valgus. Journal of Back and Musculoskeletal Rehabilitation. 2013; 26(2):163-8. https://doi.org/10.3233/BMR-2012-00363. PMid:23640317

11. Nix SE, Vicenzino BT, Smith MD. Foot pain and functional limitation in healthy adults with hallux valgus: A cross-sectional study. BMC Musculoskeletal Disorders. 2012 Dec; 13(1):1. https://doi.org/10.1186/1471-2474-13-197. PMid:23067345. PMCid:PMC3526426

12. Robinson AH, Limbers JP. Modern concepts in the treatment of hallux valgus. The Journal of Bone and Joint Surgery. 2005 Aug; 87(8):1038-45. https://doi.org/10.1302/0301-620X.87B8.16467. PMid:16049235

13. Shin JH, Lee JS, Han KH, Bae KH. Effects of foot strengthening exercises and functional insole on range of motion and foot plantar pressure in elderly women. Korean Journal of Sport Biomechanics. 2018; 28(1):45-54.

14. Wu D, Louie L. Does wearing high-heeled shoe cause hallux valgus? A survey of 1,056 Chinese Females. The Foot and Ankle. 2010; 3(5):3.

15. Wülker N, Mittag F. The treatment of hallux valgus. Deutsches Ärzteblatt International. 2012 Dec; 109(49):857. https://doi.org/10.3238/arztebl.2012.0857. PMid:23267411. PMCid:PMC3528062 